\title{
Right Reduction Mammoplasty
}

National Cancer Institute

\section{Source}

National Cancer Institute. Right Reduction Mammoplasty. NCI Thesaurus. Code C51616.

Surgery performed to reduce the size of the right breast. 